Institute for Research on Poverty

Discussion Paper no. 1044-94

\title{
Long-Term Poverty and Child Development in the United States: Results from the NLSY
}

\author{
Sanders Korenman \\ Humphrey Institute of Public Affairs and \\ Center for Population Analysis and Policy \\ University of Minnesota \\ Jane E. Miller \\ Institute for Health, Health Care Policy, and Aging Research \\ Rutgers University \\ John E. Sjaastad \\ Humphrey Institute of Public Affairs \\ University of Minnesota
}

September 1994

This research was funded by a grant from the Institute for Research on Poverty at the University of Wisconsin. An earlier version of part of this paper appeared as part of Office of Population Research Working Paper No. 93-5, Princeton University, June 1993, which contains supplemental analyses and is available from the authors. We thank participants in seminars at the University of Maryland, the University of Michigan, Princeton University, the National Bureau of Economic Research in Cambridge, Massachusetts, and the 1993 meetings of the Population Association of America for their comments. 


\begin{abstract}
The authors describe developmental deficits in early childhood associated with long-term poverty in the National Longitudinal Survey of Youth (NLSY). They compare estimates of the effects of long-term poverty (based on a thirteen-year average of income) to estimates of the effects of poverty based on a single year of income (at the time of developmental assessment). They find substantial developmental deficits among children who, on average, are poor over a number of years relative to those who are not. These deficits are approximately twice as large according to the longterm income measure as compared to those based on the single-year measure, and are not explained by differences in maternal education, family structure, maternal behaviors during pregnancy, infant health, nutritional status, or age of mother at first birth. However, an index of the home environment accounts for one-third to one-half of the developmental disadvantages (net of other factors) of children who experience long-term poverty.
\end{abstract}




\section{Long-Term Poverty and Child Development in the United States: Results from the NLSY}

\section{INTRODUCTION}

Rates of child poverty in the United States are alarmingly high and rising. In 1992, 22 percent of children were poor. Child poverty rates were, on average, one-third higher in the 1980s and early 1990s than in the 1970s. Child poverty is often long lasting. Bane and Ellwood (1986) estimate that a spell of poverty that begins with the birth of a child lasts, on average, for nearly eight years (Table 4; p. 18). Using more recent data, Duncan and Rodgers (1991) confirm the long-term nature of child poverty and find that over the past twenty years the persistence of child poverty has not fallen.

Studies of poverty duration or persistence such as these represent perhaps the most significant contribution of the past fifteen years of poverty scholarship in the United States (Duncan et al. 1984; Duncan and Rodgers 1991; Bane and Ellwood 1986; Ellwood 1988). A key insight from these studies is that poverty in the United States has a dual nature: namely, many poor persons remain impoverished for a relatively short time, while others are poor for many years. Ellwood (1988), among others, has argued that failure to recognize the heterogeneous nature and needs of the poverty population can lead to policies that are inappropriate for some or all of the poor.

Although there is growing awareness of the importance of accounting for poverty duration in describing the poverty population, in understanding the causes of poverty, and in policy formulation, little attention has been given to poverty dynamics in studies of the effects of poverty. (We review some exceptions below.) In particular, most assessments of the effects of poverty on child physical and mental development in the United States have compared children who are poor in a single year to those who are not (e.g., see the review by Goldstein [1990]). Although such studies find that poor children suffer impaired cognitive development, their "snapshot" approach may lead to understatements of the relative importance of income or poverty. On the one hand, because measured income 
fluctuates from year to year, differentials in well-being between poor and nonpoor children will be understated if single-year poverty status is used as a proxy for persistent poverty. On the other hand, because much child poverty is persistent, estimated effects of poverty based on a single year of income will reflect more than the effects of a recent poverty experience.

Aside from these methodological motivations for studying the effects of long-term poverty on children, there are ethical reasons. Persistent child poverty in the United States conflicts with fundamental social values such as equality of opportunity or the idea that each generation should be equipped with the physical and human capital to advance living standards beyond those of the generations before it.

The purpose of this paper is to describe developmental deficits in early childhood associated with long-term poverty in a national sample of U.S. children. We study a sample of children from the National Longitudinal Survey of Youth (NLSY) and compare estimates of the effects of long-term poverty (based on a thirteen-year average of income) to estimates of the effects of poverty based on a single year of income (the year of the developmental assessment). This comparison allows us to gauge the degree to which reliance upon single-year income measures may lead to understatements of the effects of poverty on child development. We also explore several hypotheses regarding the source of poor children's developmental deficits such as low parental education, single parenthood, deficits in child nutritional status, maternal behaviors (such as smoking during pregnancy) thought to be harmful to child development, and the quality of the home environment. We investigate whether estimates of the importance of these influences are sensitive to the poverty measure used (long- or short-term).

We find substantial deficits in a variety of developmental indicators between children who, on average, are poor over a number of years relative to those who are not. These deficits are larger than those based on single-year poverty measures. Developmental disadvantages associated with long-term poverty are not explained by differences in maternal education, family structure, maternal behaviors 
during pregnancy, or age of mother at first birth. However, elements of the home environment, as measured by scores on the HOME assessment (Home Observation for Measurement of the Environment), account for one-third to one-half of the developmental disadvantages of children who experience long-term poverty. This finding suggests that aspects of the home environment measured by the HOME score are important mediators of the effects of long-term poverty on child development. Further research is needed to identify the specific components of the HOME score that account for a substantial share of the long-term poverty effects.

In the next section of the paper we review studies of poverty, nutritional status, infant health outcomes, and cognitive or socioemotional development of children. We then describe the NLSY data used to estimate differentials in cognitive development according to short-term and long-term measures of family income. Simple tabulations of these differences and multivariate models are presented in the following section. Results and implications for public policy formulation are discussed in a concluding section.

\section{PREVIOUS STUDIES}

Our literature review is organized into two parts. The first encompasses studies or reviews of the association between poverty (or low socioeconomic status) and cognitive development of children. The second section includes studies that recognize nutrition as a possible mediator of the relationship between poverty and cognitive development.

\section{$\underline{\text { Poverty and Cognitive Development }}$}

Goldstein (1990) reviews several dozen studies of socioeconomic differentials in cognitive test scores in order to identify mechanisms through which these differentials arise. Of the 10 to 15 point differential in mean IQ between children in the lowest tenth of the socioeconomic distribution and 
those above the median, approximately 2 points can be attributed to four specific health problems (low birth weight, lead absorption, anemia, and ear problems), and up to an additional 7 points to differences in the home environment as measured by the score on the HOME assessment (see Appendix A and our discussion below). She notes, however, that

Virtually all studies treat social and economic status as static, usually measuring it at only one point in time in a child's life and sometimes even failing to specify when it was measured. This is a weakness, because in fact family income and parent's occupational status are quite dynamic, changing substantially from year to year. (p. 4)

In their review of the literature on child poverty, Danziger and Stern (1990) summarize several papers about the relationships among family structure, family income, and child development. Being raised in a single-parent family has a small negative effect on IQ, holding SES (socioeconomic status) constant. This finding is often interpreted as indicating that the effect of single or teen parenthood on SES (i.e., poverty) accounts for the developmental deficits of children born out of wedlock or to adolescent mothers, while age-of-mother per se has little direct effect on child outcomes once SES is controlled. They also report that children raised by single parents complete, on average, one year fewer of schooling than children from two-parent households, are less likely to have their school work monitored, and receive less supervision than do children in two-parent families, controlling for SES.

Duncan, Brooks-Gunn, and Klebanov (1994) address the need for a more careful and detailed treatment of income dynamics in studies of cognitive development. Using a sample of low-birth-weight and preterm infants born in one of eight medical centers in the United States, and followed prospectively to age five, they estimate effects on child development of persistent poverty (poor all years from birth through the fourth year of life) and transitory poverty (poor in some but not all years). They also construct a poverty dummy variable and a continuous family income-to-needs ratio, defined as family income divided by the poverty threshold, which varies by family size and age composition. 
Duncan et al. find that children who were persistently poor have greater deficits in IQ (as measured by the Wechsler Preschool and Primary Scale of Intelligence) and more behavior problems (measured by the Revised Behavior Profile) at age five than children who experienced transitory poverty, who in turn suffer IQ deficits and excess behavior problems relative to children who were never poor. These differences persist when other factors associated with poverty, such as family structure and maternal schooling, are taken into account.

They also test for the effect of neighborhood characteristics on child development. They measure neighborhood poverty by two variables: the fraction of the nonelderly population of the neighborhood living in poverty; and the fraction of families in the neighborhood with incomes below $\$ 10,000$ and the fraction with incomes over $\$ 30,000$. Age-5 IQs are significantly correlated with neighborhood status_-higher age-5 IQs are found in neighborhoods with a higher concentration of affluent neighbors, though the explanatory power of the neighborhood SES indicators is not as strong as the family-level indicators.

Geronimus, Korenman, and Hillemeier (1994) review studies that have documented the adverse impact of the young age of a mother on the cognitive and socioemotional development of children. Because teen mothers are disproportionately poor, this literature provides insights about the effects of poverty on children's development. Children of young mothers appear to suffer from cognitive and socioemotional disadvantages and are at higher risk of poor school achievement than children of older mothers. Some studies that control for SES continue to find "direct" effects of being born to a teen mother on child development while others do not. Observational studies on the parenting behaviors of teen mothers are inconclusive:

While some investigators find younger mothers to be less sensitive and responsive to their infants ... more likely to use restriction and punishment ... and less knowledgeable about parenting and child development than older mothers . . ., others find no differences by age in these areas. (p. 2) 
In addition to reviewing past studies, Geronimus et al. use NLSY data to conduct their own test of the effects of teen childbearing on the cognitive and socioemotional development of young children. They compare the development of first cousins (i.e., children of women who are sisters). After controlling for family background differences (i.e., pre-childbearing characteristics) in this manner, Geronimus et al. find no effects, direct or indirect, of teen childbearing on the cognitive and socioemotional development of young children."

Desai, Michael, and Chase-Lansdale (1990) used data from the 1986 NLSY to study the way the home environment mediates the effects of maternal employment on child development. Because they also include income controls in their models, their findings are relevant to this review. Child cognitive development is measured by the revised Peabody Picture Vocabulary Test (PPVT; see Appendix A). A child was considered poor if the average income of his family during his lifetime fell below \$13,670. Maternal employment was classified as "continuous" (employed each year); "intermittent" (employed for some period after the child's birth, but not during each year); and never employed after birth (the reference group). The quality of the home environment was measured by the HOME assessment (see Appendix A) and its cognitive stimulation and emotional support subscales. Desai et al. report a significant and positive effect of the two HOME subscales on PPVT scores. Average family income is positively related to PPVT scores, but the effect is not statistically significant.

The effect of maternal employment on children's PPVT scores differed by family income; the effect was positive for low-income boys and negative for boys from wealthier families. The authors speculate that the income provided to poor families by a working mother offsets any adverse effects of her absence. This hypothesis is supported by a regression that includes the cognitive subscale of the HOME assessment as an explanatory variable; when cognitive stimulation is held constant, the effect of maternal employment was similar in low- and middle-income families. 
Nutritional Status, Poverty, and Cognitive Development

In a review of the literature pertaining to nutritional status, growth, and cognitive development, Wilson (1981) concluded that, while the results are mixed, there is evidence that even moderate chronic malnutrition (as measured by stunting) is associated with lower scores on tests of cognitive functioning. Further, he concludes that "analyses that have been especially sensitive to the confounding effects of the environment of poverty . . continue to find a substantial relationship between nutrition and mental development" (p. 40).

Pollitt (1988) reviews evidence on the relation between poverty, birth weight, and cognitive development in both developed and developing country populations. Pollitt draws the distinction between two types of low-birth-weight (specifically, intrauterine growth retarded, IUGR) children: those who are "symmetrical" (LBW and short in length for gestational age) and those who are asymmetrical (LBW but of normal length for gestational age). Effects on cognitive development are more severe for symmetrical infants, who typically were undernourished for their entire gestation. Pollitt notes that few studies of the child development of IUGR infants discriminate between symmetrical and asymmetrical retardation.

Pollitt also reviews two large-scale studies of the effects of nutrition, health, and socioeconomic status: Broman, Nichols, and Kennedy (1975) and Wilson et al. (1986). Broman et al. analyzed relations among socioeconomic factors, nutrition, and health in a longitudinal survey of 37,945 U.S. children followed from infancy to age seven. Controlling for SES, the anthropometric indicators of nutritional status (e.g., weight and head circumference) explained a small (2 percent) but significant portion of variance in IQ at age four.

Wilson et al. studied a sample from the National Health and Nutrition Examination Survey (NHANES) of noninstitutionalized youths aged six to eleven (Cycle I) and twelve to seventeen (Cycle II). Cognitive indicators were IQ scores as measured by the Wechsler Intelligence Scale for Children 
(WISC) and the Wide Range Achievement Tests (WRAT). Family income was grouped into three categories: $<\$ 5,000, \$ 5,000-\$ 10,000$, and $>\$ 10,000$. Z-scores of height-for-age were used to indicate nutritional status and were found to be significant predictors of IQ test scores in both cycles. Height remained a significant predictor of IQ in regressions that included controls for income, race, and family size. The effect of income was significant (the construction and definition of the single income variable is not described in the paper).

Perhaps the best source of data on nutrition and child mental development comes from a longitudinal intervention study conducted in rural Guatemala by the Institute of Nutrition of Central America and Panama (INCAP), which began in 1968. Children and pregnant or lactating mothers in two villages were provided with a protein-calorie supplement. Two "comparison" villages were provided a supplement with no protein and a more diluted caloric supplementation. A wide variety of data was collected, including measures of growth, cognitive development, and the home environment. Cognitive development was measured by a preschool battery specifically designed to test language ability, short-term memory for numbers, and perceptual analysis. Prior to the intervention, the nutritional status and cognitive abilities of children of the treatment and comparison villages were found to be equivalent. The study population was poor, and over 80 percent of the children below seven years of age were identified as malnourished during the first two years of the study. Height and weight of children were among the measures of nutritional status. Housing quality (size and type of construction) was used to proxy socioeconomic status. Parents' cognitive ability, literacy, and years of schooling were also measured. These data have been analyzed by many researchers.

In their analysis of the INCAP data, Freeman et al. (1980) report that nutritional factors were highly correlated with cognitive competence among children aged three to seven years and continued to exert an independent effect on cognitive development when socioeconomic factors were controlled. For example, they report a striking association between nutritional status and performance on the 
language subtest. Head circumference and height together explained approximately 10 percent of the variance in language scores for both males and females. Social factors, including housing quality, quality of mother's clothing, and "task instruction," were also significant predictors of performance on many cognitive tests. The composite explanatory power of the social factors was also considerable; the correlations were significant $(\mathrm{p}<.01)$ for all groups except for females at age three. Lasky et al. (1981) found similar associations between infant length and weight and behavioral development among children under three years of age.

Townsend et al. (1982) analyzed a sample from the INCAP study of 550 children born between March 1969 and February 1973. The children in the treatment group in both large and small villages (with the exception of one small village) ingested more protein and were significantly taller and heavier $(\mathrm{p}<.01)$. The differences in means were fairly dramatic for both measures: as much as 2.7 centimeters ( 3 percent) at age three and 1.2 kilograms ( 9 percent) at age four. Treatment children also performed moderately better in the battery of cognitive assessments. The authors concluded that the protein supplement was responsible for the advantages in physical and mental development among children from the treatment villages. They rejected alternative explanations involving the confounding of the treatment effect by systematic pretreatment differences between comparison and treatment villages. For example, in many cases, the comparison villages and their inhabitants had more favorable pretreatment characteristics (in such areas as material stimulation, mother's vocabulary and schooling, father's schooling, and prevalence of serious illness) than the treatment villages. The comparison group also spent more time on average at the distribution centers.

In this paper we build upon and extend earlier studies of poverty, nutritional status, and child development in several respects. First, like Duncan et al. (1994), we examine the effects of long-term poverty. We focus more specifically on the adequacy of single-year income measures (corresponding to those available in many health and social surveys) for capturing the relation between economic 
deprivation and cognitive development. Second, we estimate relations between poverty and cognitive development for a national sample that includes children of all birth weights and gestational ages. Third, we include measures of nutritional deficit (stunting and wasting) at the time of assessment in models of cognitive development in order to determine whether nutritional deficits are associated with impaired cognitive development, controlling for long-term poverty. This approach builds on our earlier work in which we found substantial effects of long-term poverty on the prevalence of stunting and wasting of U.S. children (Miller and Korenman, 1994). Fourth, as suggested in the review by Pollitt, we include infant health outcomes as covariates in some models, and attempt to distinguish between symmetrical and asymmetrical IUGR. Finally, we include a wide range of indicators of cognitive development in order to determine whether results appear sensitive to the developmental indicator chosen, and to determine whether poverty or nutritional deficits are associated with particular aspects of development.

\section{DATA}

We use data from the National Longitudinal Survey of Youth (NLSY), 1979-1991. The NLSY gathered prospective information on income, nutritional status, and cognitive development for a national sample of children. The NLSY by design oversampled the poor, providing large samples of disadvantaged children. Our sample includes children born to women in the NLSY from 1979 through 1988. In some cases, we estimate separate models for Hispanics, blacks, and others. Over one-quarter of children born to NLSY women between 1979 and 1988 were born into families with incomes below the poverty line in the year of their birth (Center for Human Resource Research 1991).

The NLSY gathered information in annual interviews from a baseline cohort of approximately 6,000 women (and an equivalent number of men) ages fourteen to twenty-one in 1979. Information on infant health outcomes was collected during the first interview following the birth of a child. ${ }^{1}$ 
Cognitive assessments were administered four times: in the 1986, 1988, 1990, and 1992 Child

Supplements to the NLSY. However, 1992 assessments were not available at the time of this writing. We examine performance on a variety of cognitive assessments (described in more detail below). We use the first available assessment for each child (i.e., 1986 if it is available; if not, 1988; if 1988 is not available we use the 1990 assessment). Samples sizes vary due to nonresponse and, more importantly, due to the fact that tests are given to children only at specific ages. Sample sizes for the models range from 1,939 for the Digit Span (given to children age seven and older) to 3,826 for the Peabody Picture Vocabulary Test (given to children age three and over). Sample sizes for each outcome are shown at the bottom of Table 4, and these are further broken down by long-term poverty category in Table A5.

\section{VARIABLES}

\section{$\underline{\text { Cognitive and Socioemotional Development }}$}

Early childhood and socioemotional development is measured by seven psychometric instruments (tests) and an index of behavior problems (Center for Human Resource Research 1991). These indicators are defined and described briefly in Table A1 (reprinted in modified form from Geronimus, Korenman, and Hillemeier [1994], which summarizes information in Baker and Mott [1989]). For a discussion of assessment validity, see Baker and Mott (1989). In some models, we introduce controls for characteristics of the home environment as measured by the HOME (Home Observation for Measurement of the Environment) assessment. The HOME assessment in the NLSY includes a subset of the questions from the original HOME inventory (Caldwell and Bradley 1979); analyses of these items have shown that they adequately capture the dimensions of the home environment that were measured by the larger set of questions (Parcel and Menaghan 1989).

The HOME assessment consists of two parts: (1) interviewer observations of mother-child interaction and safety/appearance of the home; and (2) maternal reports of child interactions with adult 
family members, discipline methods, and materials and activities available to the child, which address factors affecting cognitive stimulation and emotional support. Items differ for children aged 0 to 2 years, 3 to 5 years, 6 to 9 years, and 10 years and older.

All outcomes are age-standardized percentile scores. Exceptions are the Behavior Problems Index, which is age- and sex-standardized, and the Digit Span (SPAN), which is scored on a scale of one to twenty. We multiplied the Digit Span scores by five so it would have the same (potential) range as the other outcomes.

$\underline{\text { Income and Poverty Status }}$

The income-to-needs ratio for each year is calculated by dividing family income by the U.S. Census poverty line, which varies according to family size and age composition and is adjusted for inflation (U.S. Bureau of the Census 1983). We define five categories of income/needs that correspond to groups of social and policy interest: family income below half the poverty line; income between 0.5 and 1.0 times the poverty line; income between the poverty line and 1.85 times the poverty line; income between 1.85 and 3.0 times the poverty line; and income above 3.0 times the poverty line, the reference category. ${ }^{2}$ There is growing scholarly interest in the extremely poor-those with incomes below half the poverty line (e.g., Blackburn 1993). We found in earlier work (Miller and Korenman 1994) that the incidence of LBW births was higher among the extremely poor than among persons with incomes closer to the poverty line.

We define both long-term and short-term measures of income/needs. Long-term income is measured by the thirteen-year income/needs ratio (1978 to 1990). It represents the average economic standing of the family into which children are born and in which they live, and captures income during pregnancy and childhood. The long-term measure smoothes annual fluctuations in income that are due either to measurement error or to genuine changes in economic standing. Income at assessment (or 
current income) is based on the single-year income/needs ratio for the calendar year of the child supplement.

Child Nutritional Status, Infant Health Outcomes, and Smoking and Drinking during Pregnancy

The literature reviewed above indicated that poor child health, malnutrition, and adverse infant health outcomes may, in part, mediate the relationship between poverty and child development. We therefore include three indicators of infant health at birth in our models of child development: "prematurity" (gestational age <37 weeks); low birth weight (LBW; birthweight $<5.5$ pounds); and "short" (length <19 inches at birth). We include an interaction of low birth weight and short length at birth as a rough test for differences (suggested by Pollitt) between children who are symmetrically IUGR (LBW and short) and those who are asymmetrically IUGR (LBW but of normal length). ${ }^{3}$ Because of interest in how adverse maternal behaviors during pregnancy may affect child development, we also include a set of dummy variables, based on maternal reports, for cigarette smoking and alcohol drinking by the mother during the year prior to the child's birth. The categories for alcohol drinking in the year before birth are: none; drank in the year before birth but fewer than one drink per month during pregnancy; fewer than one drink per week during pregnancy; more than one drink per week during pregnancy. The categories of cigarette smoking are: did not smoke in the year prior to birth; smoked in the year prior to birth but not during pregnancy; smoked during pregnancy but less than one pack per day; smoked one pack per day or more during pregnancy. ${ }^{4}$

We include two indicators of deficits in nutritional status in models of child development. Several of the studies reviewed above (e.g., the INCAP studies) reported adverse effects of nutritional deprivation on early childhood development. In addition, we found that the odds of being stunted (below the 10th percentile of NCHS standards in height-for-age) or wasted (below the 10th percentile of NCHS standards in weight-for-height) (Sullivan and Gorstein 1990) were elevated among children who experienced long-term poverty (Miller and Korenman 1993). Therefore, we include dummy 
variables that indicate whether the child was stunted or wasted at the time of the pertinent child assessment. It is important to keep in mind that stunting and wasting are not direct measures of dietary deficiencies (World Health Organization 1986). Stunting and wasting are measures of a child's nutritional history and his nutritional status, and they reflect experience with childhood diseases, health care, etc. As Pollitt (p. 68) notes, "Growth retardation is not a 'proxy for nutrition'; it is only an index of nutritional status" (Beaton 1983).

\section{$\underline{\text { Maternal Characteristics }}$}

We include in models of child development a set of maternal characteristics in order to assess hypotheses regarding factors that might account for or mediate the relationship between poverty and child development. These characteristics include: the mother's score on the Armed Forces Qualifying Test (AFQT), administered to sample members in 1980; marital status at assessment to proxy family structure (never married; divorce/separated; the reference category is currently married) $;{ }^{5}$ mother's age at first birth; and dummy variables for years of schooling completed as of the 1991 interview (less than twelve years; twelve years; the reference category is education beyond high school).

\section{DESCRIPTIVE ANALYSES}

In Table 1 we present means of indicators of cognitive and socioemotional development (described in detail in Table A1) for sample children by long-term income/needs ratio and black or Hispanic identification. A higher score represents a more favorable outcome in all cases except the BPI (Behavior Problems Index), for which a lower score indicates fewer behavior problems. Lower income is associated with poorer scores on all outcomes, dramatically lower in the cases of the PPVT (vocabulary) and the PIAT (math and reading achievement) tests. Differences in income are also apparent within each racial/ethnic group. The low scores among Hispanics may reflect 
English-language difficulties, although Spanish-language tests were available. Lower scores among minorities may also reflect bias in the content and wording of the instruments.

In Table 2 we present sample means and frequencies by long-term income/needs ratios.

Sample children who are long-term poor are almost exclusively black or Hispanic (73 percent of the two long-term poverty groups combined). The fraction of children with deficits in nutritional status (wasted or stunted) tends to be highest among the poor, as does the fraction born LBW, premature, and short (<19 inches in length). Regular drinking and heavy smoking during pregnancy appears to be somewhat higher among the poor as well. Poor children tend to be older, of higher birth order, and from larger families than non-poor children in the sample. The AFQT score of the mother rises sharply with income, as does the fraction who had completed education beyond high school by 1991 . (The fraction with some postsecondary education rises from less than 2 percent of the poorest women to nearly 60 percent of women in the $3.0+$ income/needs category.) The sharp differences in these maternal and infant and child health characteristics across income categories suggest the need for estimation of multivariate models in order to calculate a "partial" effect of income, and those sharp differences support the proposition that many of these characteristics are good candidates for variables that mediate or account for the relationship between poverty and child development. 
TABLE 1

Mean Percentile Scores on Tests of Child Cognitive and Socioemotional Development, by Long-Term Income/Needs Ratio

\begin{tabular}{|c|c|c|c|c|c|c|c|c|}
\hline $\begin{array}{l}\text { 13-Year } \\
\text { Income/Needs Ratio }\end{array}$ & PPVT & SPAN & $\mathrm{BPI}^{\mathrm{a}}$ & PIATM & PIATRR & PIATRC & VMAB & VMC \\
\hline \multicolumn{9}{|l|}{ All } \\
\hline$\overline{<0} .5$ & 8 & 43 & 66 & 30 & 43 & 47 & 31 & 30 \\
\hline $0.5-1.0$ & 14 & 43 & 68 & 35 & 47 & 49 & 36 & 37 \\
\hline $1.0-1.85$ & 27 & 48 & 64 & 45 & 55 & 57 & 43 & 41 \\
\hline $1.85-3.0$ & 38 & 49 & 61 & 52 & 63 & 66 & 45 & 45 \\
\hline $3.0+$ & 49 & 52 & 56 & 58 & 69 & 69 & 47 & 45 \\
\hline \multicolumn{9}{|l|}{ Hispanics } \\
\hline$<0.5$ & 7 & 42 & 72 & 16 & 22 & 26 & 20 & 14 \\
\hline $0.5-1.0$ & 11 & 40 & 66 & 33 & 39 & 44 & 27 & 35 \\
\hline $1.0-1.85$ & 21 & 46 & 63 & 39 & 50 & 55 & 33 & 37 \\
\hline $1.85-3.0$ & 27 & 46 & 60 & 48 & 55 & 61 & 38 & 42 \\
\hline $3.0+$ & 39 & 52 & 54 & 52 & 62 & 64 & 42 & 48 \\
\hline \multicolumn{9}{|l|}{ Non-Hispanic Blacks } \\
\hline$<0.5$ & 7 & 43 & 67 & 32 & 45 & 48 & 34 & 33 \\
\hline $0.5-1.0$ & 10 & 44 & 68 & 35 & 50 & 51 & 40 & 38 \\
\hline $1.0-1.85$ & 16 & 50 & 61 & 44 & 60 & 58 & 46 & 44 \\
\hline $1.85-3.0$ & 21 & 49 & 63 & 48 & 65 & 67 & 47 & 49 \\
\hline $3.0+$ & 27 & 52 & 59 & 52 & 70 & 70 & 46 & 45 \\
\hline \multicolumn{9}{|c|}{ Non-Hispanic Whites and Others } \\
\hline$<0.5$ & 17 & 40 & 56 & 33 & 50 & 66 & 26 & 30 \\
\hline $0.5-1.0$ & 25 & 44 & 69 & 37 & 45 & 49 & 36 & 37 \\
\hline $1.0-1.85$ & 37 & 48 & 67 & 50 & 55 & 58 & 45 & 42 \\
\hline $1.85-3.0$ & 46 & 51 & 60 & 55 & 64 & 68 & 47 & 45 \\
\hline $3.0+$ & 53 & 52 & 56 & 60 & 70 & 70 & 47 & 45 \\
\hline
\end{tabular}

Source: 1979-1991 National Longitudinal Survey of Youth.

Notes: See Table A1 for names and descriptions of tests. Long-term income/needs is a thirteen-year average, $1978-1990$. SPAN is raw score $(\max =20)$ times five; all others are age-standardized percentile scores.

${ }^{\mathrm{a}} \mathrm{A}$ higher BPI score indicates more behavior problems. 
TABLE 2

Characteristics of Sample Children, by Thirteen-Year Income/Needs Ratio (percents unless indicated)

\begin{tabular}{|c|c|c|c|c|c|}
\hline & $<0.5$ & $0.5-1.0$ & $1.0-1.85$ & $1.85-3.0$ & $3.0+$ \\
\hline 13-year income/needs ratio & 0.4 & 0.7 & 1.4 & 2.4 & 4.1 \\
\hline 1-year income/needs ratio & 0.5 & 0.8 & 1.5 & 2.4 & 4.1 \\
\hline Wasted $^{\mathrm{a}}$ & 16.9 & 12.6 & 11.1 & 12.5 & 10.2 \\
\hline Stunted $^{\mathrm{a}}$ & 15.1 & 15.7 & 13.3 & 12.1 & 9.2 \\
\hline Age of child (mos) ${ }^{a}$ & 63.3 & 59.3 & 59.2 & 55.1 & 43.4 \\
\hline Black & 63.8 & 47.9 & 31.5 & 17.7 & 7.4 \\
\hline Hispanic & 17.9 & 23.2 & 23.2 & 17.6 & 12.3 \\
\hline Boy & 51.8 & 51.3 & 50.2 & 51.8 & 52.2 \\
\hline Number of siblings ${ }^{a}$ & 1.2 & 1.7 & 1.3 & 1.0 & 0.8 \\
\hline First born & 14.7 & 31.7 & 44.2 & 55.1 & 63.0 \\
\hline Mother's AFQT & 36.9 & 42.0 & 55.5 & 67.7 & 78.3 \\
\hline Mother's age at 1st birth (yrs.) & 17.5 & 18.7 & 19.7 & 21.1 & 23.4 \\
\hline Never married ${ }^{\mathrm{a}}$ & 48.2 & 38.5 & 16.0 & 7.3 & 2.8 \\
\hline Divorced/separated ${ }^{\mathrm{a}}$ & 25.0 & 30.4 & 25.2 & 17.6 & 9.1 \\
\hline$<$ HS grad & 69.3 & 48.2 & 27.7 & 11.5 & 5.1 \\
\hline$=\mathrm{HS} \operatorname{grad}$ & 28.9 & 40.4 & 50.3 & 56.7 & 38.9 \\
\hline LBW & 8.5 & 11.3 & 9.1 & 6.3 & 4.3 \\
\hline Short at birth & 20.1 & 16.0 & 13.5 & 9.3 & 7.5 \\
\hline
\end{tabular}

(table continues) 
TABLE 2, continued

\begin{tabular}{|c|c|c|c|c|c|}
\hline & $<0.5$ & $0.5-1.0$ & $1.0-1.85$ & $1.85-3.0$ & $3.0+$ \\
\hline LBW $*$ short & 3.0 & 5.1 & 4.7 & 3.9 & 2.0 \\
\hline Gestation < 37 wks. & 7.1 & 9.6 & 8.6 & 6.5 & 4.9 \\
\hline \multicolumn{6}{|l|}{ Alcohol use during pregnancy $^{\mathrm{b}}$} \\
\hline Drank, but $<1$ drink/month & 8.7 & 14.3 & 20.7 & 29.1 & 37.9 \\
\hline$\geq 1$ drink per month, $<1$ per week & 6.4 & 11.7 & 9.7 & 12.8 & 18.9 \\
\hline$\geq 1$ drink/week & 8.3 & 6.2 & 3.2 & 3.5 & 4.0 \\
\hline \multicolumn{6}{|l|}{ Smoking, year prior to birth ${ }^{\mathrm{b}}$} \\
\hline Smoked, but not while pregnant & 1.4 & 1.9 & 2.9 & 3.5 & 4.8 \\
\hline$<1$ pack/day while pregnant & 24.8 & 24.2 & 22.6 & 20.4 & 17.6 \\
\hline$\geq 1$ pack/day while pregnant & 6.0 & 13.6 & 9.8 & 8.8 & 5.0 \\
\hline Sample size (max.) & 218 & 1137 & 1704 & 1429 & 995 \\
\hline
\end{tabular}

Source: 1979-1991 National Longitudinal Survey of Youth.

aTime-varying covariate; figure shown is for 1988.

${ }^{b}$ Reference groups are: did not smoke in the year before birth of child; did not drink alcohol in the year before birth of child. 
In Table 3 we present unadjusted correlations of single-year income/need ratios, thirteen-year income/needs ratios, and the HOME assessment, with scores on the cognitive development tests. Several patterns are worth noting. First, the correlation of cognitive development measures with longterm income is somewhat higher (in absolute value) than the corresponding correlation with short-term income. Second, correlations between the HOME score at the time of assessment and the cognitive outcomes are similar to the corresponding correlations between the long-term income/needs ratio and the cognitive outcomes. The correlation between the HOME score and long-term income/need ratio is about 0.4 , and the correlation between short-term and long-term income is about 0.7 to 0.8 . Finally, the correlation between long-term income/needs ratios or the HOME scores and the cognitivedevelopment test scores appears to be somewhat weaker among black children than among Hispanic or white children (i.e., "other non-Hispanics").

\section{$\underline{\text { Results from Multivariate Analyses }}$}

In Table 4 we present four sets of coefficients from least-squares regressions of the cognitive development measures on variables representing categories of thirteen-year income/needs ratios. The first set of models includes, in addition to the income dummy variables, age of child at assessment, indicators of black and Hispanic identification, sex of child, number of siblings, and birth order (a dummy variable for first born). According to these assessments, there are large differentials in cognitive development between low-income and higher-income children.

In the second set of models we add variables reflecting maternal characteristics (AFQT score; dummy variables for < HS graduate or HS graduate; age of mother at first birth; and marital status in the year of assessment). Although the relations between long-term poverty and each of the cognitive variables are similar to those in the first set of models, the coefficients are about half as large, and some of the effects (e.g., verbal memory scales VMAB and VMC) are no longer significant at the .05 
TABLE 3

Correlations between Scores on Tests of Child Cognitive or Socioemotional Development and Long-Term Income/Needs Ratio, Short-Term Income/Needs Ratio, and HOME Scores

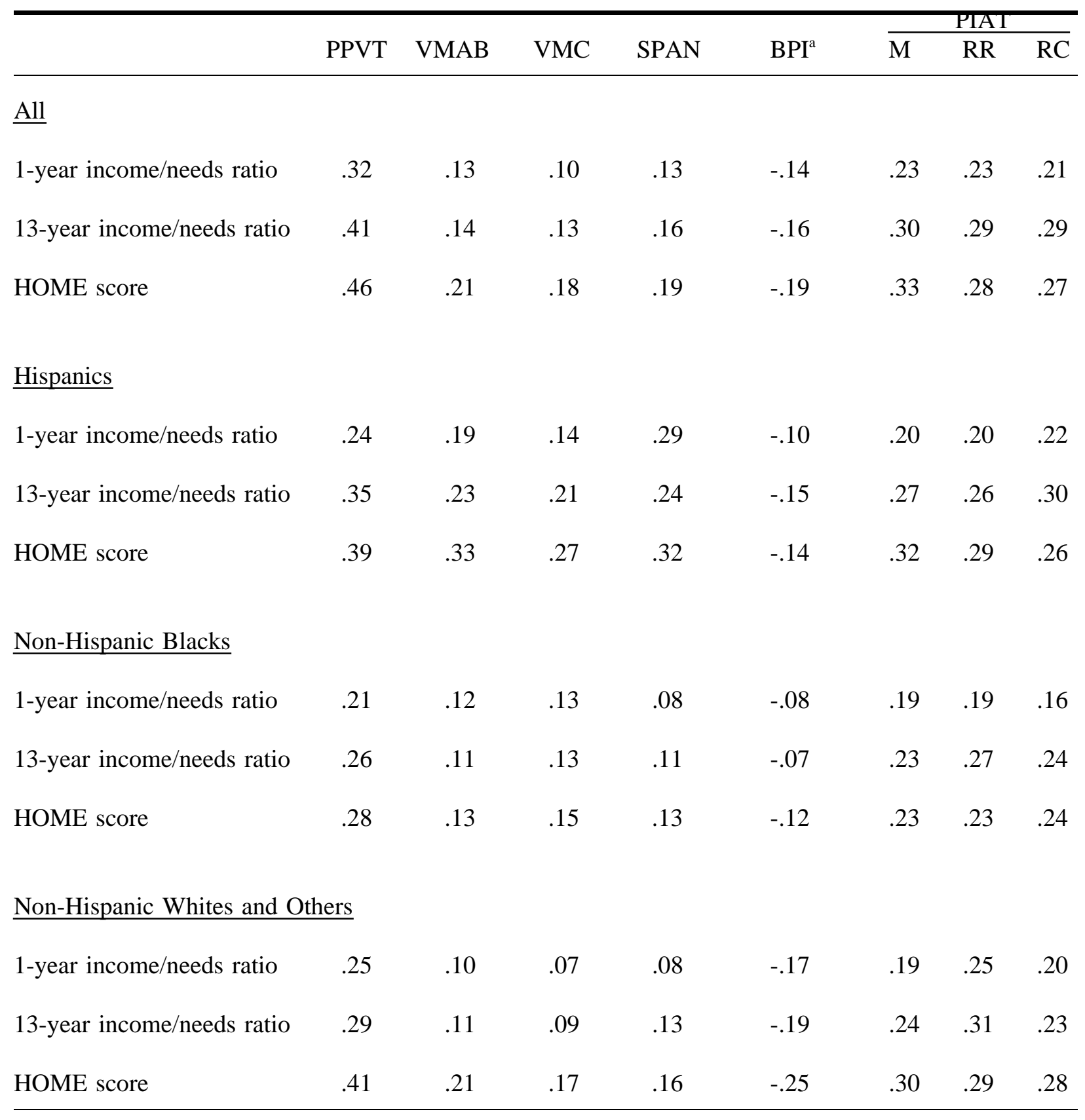

Source: 1979-1991 National Longitudinal Survey of Youth.

Notes: See Table A1 for names and descriptions of tests. Long-term income/needs ratio is thirteenyear average, $1978-1990$. SPAN is raw score $(\max =20)$ times five; all others are age-standardized percentile scores.

${ }^{\mathrm{a} A}$ higher BPI score indicates more behavior problems. 
TABLE 4

Effects of Long-Term Poverty on Child Socioemotional and Cognitive Development, Various Specifications

(Dependent Variable $=$ Assessment Score in Percentiles)

13-Year Income/Needs Ratio

(1) Basic controls

$\begin{array}{lcccccccc}<0.5 & -24.8^{*} & -14.2^{*} & -12.0^{*} & -10.1^{*} & 12.3^{*} & -24.0^{*} & -23.2^{*} & -11.9^{*} \\ 0.5-1.0 & -22.9^{*} & -8.5^{*} & -5.8^{*} & -9.2^{*} & 13.3^{*} & -19.0^{*} & -19.8^{*} & -11.3^{*} \\ 1.0-1.85 & -15.2^{*} & -2.2 & -2.1 & -4.1^{*} & 9.1^{*} & -10.8^{*} & -11.5^{*} & -6.0^{*} \\ 1.85-3.0 & -8.3^{*} & 0.0 & 1.1 & -2.4^{*} & 5.3^{*} & -4.8^{*} & -5.3^{*} & -0.4\end{array}$

(2) Controls in (1) plus maternal characteristics

$\begin{array}{lrrrrrrrr}<0.5 & -10.5^{*} & -3.4 & -5.3 & -6.2^{*} & 4.6 & -11.7^{*} & -11.2^{*} & -6.4^{*} \\ 0.5-1.0 & -10.6^{*} & 0.5 & -0.4 & -5.7^{*} & 7.2^{*} & -8.6^{*} & -9.8^{*} & -6.4^{*} \\ 1.0-1.85 & -7.8^{*} & 3.1^{*} & 1.2 & -2.1 & 5.6^{*} & -4.6^{*} & -5.8^{*} & -3.3^{*} \\ 1.85-3.0 & -4.7^{*} & 2.6 & 2.8 & -1.6 & 3.8^{*} & -2.0 & -2.9^{*} & 0.8\end{array}$

(3) Controls in (2) plus stunted and wasted

$\begin{array}{lrlrlllll}<0.5 & -10.1^{*} & -3.1 & -5.1 & -5.9^{*} & 4.8 & -11.6^{*} & -11.1^{*} & -7.0^{*} \\ 0.5-1.0 & -10.3^{*} & 0.7 & -0.2 & -5.5^{*} & 7.3^{*} & -8.2^{*} & -9.5^{*} & -6.3^{*} \\ 1.0-1.85 & -7.7^{*} & 3.2^{*} & 1.3 & -2.0 & 5.6^{*} & -4.5^{*} & -5.8^{*} & -3.1^{*} \\ 1.85-3.0 & -4.6^{*} & 2.7 & 2.8 & -1.6 & 3.8^{*} & -1.9 & -2.8 & 0.8\end{array}$

(4) Controls in (3) plus infant health, smoking and drinking

\begin{tabular}{lcccccccc}
$<0.5$ & $-10.0^{*}$ & -2.5 & -4.7 & $-5.8^{*}$ & 5.4 & $-11.3^{*}$ & $-11.0^{*}$ & $-6.9^{*}$ \\
$0.5-1.0$ & $-10.1^{*}$ & 1.0 & -0.1 & $-5.3^{*}$ & $7.1^{*}$ & $-7.8^{*}$ & $-9.0^{*}$ & $-6.1^{*}$ \\
$1.0-1.85$ & $-7.5^{*}$ & $3.3^{*}$ & 1.2 & -2.0 & $5.7^{*}$ & $-4.2^{*}$ & $-5.3^{*}$ & -2.9 \\
$1.85-3.0$ & $-4.4^{*}$ & 2.6 & 2.8 & -1.6 & $3.8^{*}$ & -1.7 & -2.4 & 0.9 \\
& & & & & & & & \\
& & & & & & & & \\
Mean of dependent variable & 29.4 & 42.0 & 41.3 & 47.4 & 62.8 & 45.7 & 56.5 & 59.3 \\
Sample size & 3826 & 3694 & 3626 & 1639 & 3596 & 3043 & 3004 & 2483 \\
\hline
\end{tabular}

Source: Authors' calculations based on 1979-1991 National Longitudinal Survey of Youth.

Models: (1) Controls include: age of child, number of sibs., and dummy variables for black and Hisp. identification, boy, and first born. (2) Controls in (1) plus Mother's AFQT score, age at first birth, and dummy variables for marital status (2) and schooling (2). (3) Controls in (2) plus dummy variables for stunted and wasted at assessment. (4) Controls in (3) plus dummy variables for LBW, short at birth, LBW*short, gestational age < 37 weeks, and smoking (3 dummy variables) and alcohol drinking during pregnancy (3 dummy variables).

Notes: See Table A1 for names and descriptions of the tests. SPAN is raw score $(\max =20)$ times five; all others are age-standardized percentile scores.

${ }^{\mathrm{a}} \mathrm{A}$ higher BPI score indicates more behavior problems.

$* \mathrm{p} \leq .05$. 
level. Adding the maternal AFQT score alone is responsible for one-half to three-quarters of the drop in the effect of poverty between the first and second sets of models (separate results not shown).

In the third set of models we add indicators of poor nutritional status at assessment (low weight-for-height and low height-for-age). As we will see later (Table 5), although they often enter with significant coefficients, their addition to the model has little effect on the coefficients of longterm income. Finally, in the fourth set of models, we add controls for infant health outcomes (LBW, short at birth, an interaction of LBW and short, premature birth, and maternal reports of smoking and alcohol drinking during pregnancy). The addition of these variables changes little the income effects.

In Table 5 we present the full set of coefficients from the fourth set of models (the most detailed) summarized in Table 4. Controlling for long-term income, maternal characteristics, nutritional status at assessment, smoking and alcohol drinking, and infant health outcomes, black racial identification is associated with lower scores on the PPVT test only, and with higher scores on the VMAB, VMC, SPAN, and PIATRR assessments. Hispanic identification is associated with lower scores for four of the eight outcomes.

Girls, first-born children, and those from smaller families do better according to several outcomes. As noted, mother's AFQT score is a strong predictor of child performance on cognitive tests. Low maternal educational attainment is also associated with lower test scores. Mother's age at first birth is generally positively related to child performance, but the effect is never statistically significant. We find little difference in cognitive development measures according to family structure as proxied by mother's marital status at assessment. Married mothers (the reference category) do report fewer behavior problems.

Stunting and wasting are associated with lower test scores, with at least one of the two variables having a statistically significant coefficient in six of the eight outcomes. Short-term memory, as measured by the Memory for Digit Span (SPAN) score, appears particularly sensitive to 
TABLE 5

Models of Child Socioemotional and Cognitive Development (Dependent Variable $=$ Assessment Score in Percentiles)

\begin{tabular}{|c|c|c|c|c|c|c|c|c|}
\hline & PPVT & VMAB & VMC & SPAN & $\mathrm{BPI}^{\mathrm{a}}$ & PIATM & PIATRR & PIATRC \\
\hline \multicolumn{9}{|l|}{ 13-Year Income/Needs Ratio } \\
\hline$<0.5$ & $-10.0 *$ & -2.5 & -4.7 & $-5.8 *$ & 5.4 & $-11.3 *$ & $-11.0^{*}$ & $-6.9 *$ \\
\hline $0.5-1.0$ & $-10.1^{*}$ & 1.0 & -0.1 & $-5.3^{*}$ & $7.1^{*}$ & $-7.8^{*}$ & $-9.0^{*}$ & $-6.1 *$ \\
\hline $1.0-1.85$ & $-7.5^{*}$ & $3.3^{*}$ & 1.2 & -2.0 & $5.7^{*}$ & $-4.2^{*}$ & $-5.3 *$ & -2.9 \\
\hline $1.85-3.0$ & $-4.4^{*}$ & 2.6 & 2.8 & -1.6 & $3.8^{*}$ & -1.7 & -2.4 & 0.9 \\
\hline Black & $-18.0 *$ & $4.3^{*}$ & $3.9^{*}$ & $2.3^{*}$ & -1.0 & -2.2 & $5.9^{*}$ & 1.9 \\
\hline Hispanic & $-12.9^{*}$ & $-6.0 *$ & -1.1 & -0.3 & -0.9 & $-4.7 *$ & $-3.6^{*}$ & -0.3 \\
\hline Boy & -1.3 & $-7.8^{*}$ & $-4.5^{*}$ & $-2.5^{*}$ & -1.1 & $-3.2^{*}$ & $-5.3^{*}$ & $-2.0^{*}$ \\
\hline First born & $3.4^{*}$ & -0.7 & $2.3^{*}$ & -0.7 & $3.7^{*}$ & 0.9 & $6.0^{*}$ & $2.6^{*}$ \\
\hline Number of siblings & $-1.1^{*}$ & $-1.2 *$ & $-1.5^{*}$ & -0.2 & 0.7 & -0.7 & $-1.2^{*}$ & $-1.8^{*}$ \\
\hline Mother's AFQT & $0.3^{*}$ & $0.2 *$ & $0.1^{*}$ & $0.1^{*}$ & -0.1 & $0.3^{*}$ & $0.3^{*}$ & $0.2 *$ \\
\hline Mother's age at 1st birth (yrs.) & 0.3 & 0.4 & 0.2 & 0.1 & -0.2 & 0.4 & 0.1 & -0.1 \\
\hline Never married & -0.7 & -1.2 & -0.8 & 0.0 & $3.8^{*}$ & 0.1 & -0.9 & -0.1 \\
\hline Divorced/separated & 0.7 & 2.0 & $2.5^{*}$ & 0.6 & $3.7^{*}$ & 0.3 & 0.7 & 1.3 \\
\hline$<\mathrm{HS}$ grad & $-3.5^{*}$ & -3.0 & -3.1 & -0.5 & 2.5 & $-3.1 *$ & $-4.0^{*}$ & 0.3 \\
\hline$=$ HS grad & $-2.3^{*}$ & -1.2 & -1.9 & -0.3 & 0.9 & -1.4 & $-2.4 *$ & -0.9 \\
\hline Stunted & $-3.0^{*}$ & $-3.6^{*}$ & 0.6 & $-5.7^{*}$ & -1.3 & $-4.4^{*}$ & -1.8 & -2.5 \\
\hline Wasted & $-2.6^{*}$ & -0.9 & $-3.7 *$ & -0.3 & -1.4 & -2.5 & $-3.8^{*}$ & -0.3 \\
\hline LBW & -1.4 & -4.0 & -0.4 & -1.5 & -1.5 & $-4.8^{*}$ & -2.3 & -0.2 \\
\hline Short at birth & 0.2 & $-3.8 *$ & -3.2 & 1.3 & -0.8 & -1.2 & 1.2 & 1.1 \\
\hline LBW*Short & -1.4 & 3.8 & 4.4 & $-6.2 *$ & -0.2 & 0.5 & $-7.2^{*}$ & -1.7 \\
\hline Gestation < 37 wks. & 0.2 & 0.3 & -1.0 & 2.4 & 1.4 & 2.3 & 0.4 & -2.6 \\
\hline \multicolumn{9}{|l|}{ Alcohol use year prior to birth } \\
\hline $\begin{array}{l}<1 \mathrm{drink} / \text { month } \\
\geq 1 \mathrm{drink} / \text { month }\end{array}$ & 0.6 & 2.2 & -0.2 & 1.7 & 1.6 & 2.1 & 1.6 & 0.0 \\
\hline$<1 \mathrm{drink} /$ week & -1.0 & -2.0 & 0.6 & -1.7 & $3.3^{*}$ & 0.3 & 0.1 & -1.5 \\
\hline$\geq 1$ drink/week & -1.3 & -3.7 & $-5.2 *$ & 0.0 & 3.3 & -1.4 & 1.2 & -0.9 \\
\hline \multicolumn{9}{|l|}{ Smoking, year prior to birth } \\
\hline Smoked, but not while pregnant & 0.8 & 3.2 & 0.4 & 0.3 & 1.2 & 2.5 & 1.7 & -0.2 \\
\hline$<1$ pack/day while pregnant & 0.3 & 2.2 & 1.5 & 0.9 & 1.5 & 1.3 & 0.0 & 0.8 \\
\hline$\geq 1$ pack/day while pregnant & -2.4 & 0.4 & -0.1 & 0.9 & $7.5^{*}$ & -1.5 & -2.5 & -0.3 \\
\hline
\end{tabular}

Source: Authors' calculations based on 1979-1991 National Longitudinal Survey of Youth.

Notes: See Table A1 for names and descriptions of tests. Long-term income/needs ratio is a thirteen-year average, 1978-1990. A control for age of child at assessment (in months) is included in all models. SPAN is raw score (max=20) times five; all others are age-standardized percentile scores. Sample sizes appear at the bottom of Table 4.

${ }^{\mathrm{a}} \mathrm{A}$ higher BPI score indicates more behavior problems.

$* \mathrm{p} \leq .05$. 
deficits in height-for-age (stunting). The effect of stunting is one of the largest in the model, equivalent to the difference between a thirteen-year average income below the poverty line and one that is more than three times the poverty line.

Among the infant health outcomes included in the model, LBW was consistently negatively related to cognitive development, although only one main effect of LBW is statistically significant (PIATM). In addition, two of the interactions between LBW and short at birth are significant (SPAN and PIATRR), such that children who are both short and LBW (symmetric IUGR) have lower scores than those who have only one of these attributes. Short gestation does not appear to have statistically significant partial effects, perhaps because of substantial measurement error, evidenced by severe heaping of gestation reports in the NLSY (see, for example, the discussion in Currie and Cole [1991]), or perhaps because of collinearity with the two other birth outcomes included in the models. Finally, although the effects of smoking and alcohol drinking during pregnancy have the expected signs, they are rarely statistically significant, and adding them to the models has little effect on the estimated effects of poverty. ${ }^{6}$

In Table 6 we compare coefficients from models that include, alternatively, thirteen-year and single-year (i.e., "at assessment") income measures. The model specifications are those reported in Table 5. It is evident from these comparisons that the differentials in scores on cognitive assessments are larger and more consistently statistically significant according to the long-term than short-term poverty measure. For PPVT, VMC, SPAN, and PIAT scores, the deficit for the poorest group relative to the high-income group is two to three times larger when we use a long-term, rather than a shortterm, measure of income. In supplemental analyses (Miller and Korenman 1993, Table A5), we demonstrated that differences in effects according to a relative measure (comparing the bottom quartile of the long- or short-term income distribution to the top quartile) are similar to the differences according to the absolute measure used in the models shown here. ${ }^{7}$ 
TABLE 6

Comparison of Effects of Short-Term and Long-Term Poverty on Scores on Tests of Child Cognitive Development: OLS Coefficients

\begin{tabular}{|c|c|c|c|c|}
\hline $\begin{array}{l}\text { Tests of Child } \\
\text { Development } \\
\text { (Dependent Variables) }\end{array}$ & $<0.5$ & $0.5-1.0$ & $1.0-1.85$ & $1.85-3.0$ \\
\hline \multicolumn{5}{|l|}{ PPVT } \\
\hline 1. 13-year & $-10.0^{*}$ & $-10.1^{*}$ & $-7.5^{*}$ & $-4.4^{*}$ \\
\hline 2. 1-year & $-4.6^{*}$ & $-6.6 *$ & $-6.1^{*}$ & $-2.6^{*}$ \\
\hline \multicolumn{5}{|l|}{$\underline{\mathrm{VMAB}}$} \\
\hline 1. 13-year & -2.5 & 1.0 & $3.3^{*}$ & 2.6 \\
\hline 2. 1-year & -0.4 & -1.6 & -0.6 & 1.8 \\
\hline \multicolumn{5}{|l|}{$\underline{\mathrm{VMC}}$} \\
\hline 1. 13-year & -4.7 & -0.1 & 1.2 & 2.8 \\
\hline 2. 1-year & -0.6 & -1.6 & -0.7 & 2.0 \\
\hline \multicolumn{5}{|l|}{ SPAN } \\
\hline 1. 13-year & $-5.8^{*}$ & $-5.3 *$ & -2.0 & -1.6 \\
\hline 2. 1-year & -2.1 & -1.0 & -1.4 & 0.2 \\
\hline \multicolumn{5}{|l|}{$\underline{\mathrm{BPI}}^{\mathrm{a}}$} \\
\hline 1. 13-year & 5.4 & $7.1^{*}$ & $5.7 *$ & $3.8 *$ \\
\hline 2. 1-year & $7.2 *$ & $4.8^{*}$ & $6.6^{*}$ & $4.7 *$ \\
\hline \multicolumn{5}{|l|}{$\underline{\text { PIATM }}$} \\
\hline 1. 13-year & $-11.3^{*}$ & $-7.8 *$ & $-4.2 *$ & -1.7 \\
\hline 2. 1-year & -3.7 & $-5.8 *$ & -2.0 & -0.8 \\
\hline \multicolumn{5}{|l|}{ PIATRR } \\
\hline 1. 13-year & $-11.0^{*}$ & $-9.0 *$ & $-5.3 *$ & -2.4 \\
\hline 2. 1-year & $-4.9 *$ & $-5.5^{*}$ & $-4.0 *$ & -0.8 \\
\hline \multicolumn{5}{|l|}{ PIATRC } \\
\hline 1. 13-year & $-6.9 *$ & $-6.1 *$ & -2.9 & -0.9 \\
\hline 2. 1-year & $-4.6^{*}$ & $-5.9 *$ & $-3.8^{*}$ & -1.1 \\
\hline
\end{tabular}

Source: Authors' calculations based on 1979-1991 National Longitudinal Survey of Youth.

\section{Model specifications:}

1. Includes 13-year income/needs dummy variables.

2. Includes 1-year income/needs dummy variables.

Notes: Controls include, in addition to income variables, dummy variables for black and Hispanic, boy, first born, marital status (2 dummy variables), schooling (2 dummy variables), LBW, short at birth, LBW*short, gestation <37 weeks, alcohol drinking (3 dummy variables) and smoking (3 dummy variables) during pregnancy, and controls for mother's AFQT, age of child at assessment (in months), number of siblings, and age at first birth. See Table A1 for names and descriptions of the tests. Sample sizes appear at the bottom of Table 4. SPAN is raw score $(\max =20)$ times five; all others are age-standardized percentile scores.

${ }^{\mathrm{a}} \mathrm{A}$ higher BPI score indicates more behavior problems.

$* \mathrm{p} \leq .05$. 
Coefficients (not shown) of variables other than income/needs in models with short-term measures of income are similar in both magnitude and significance to the corresponding coefficients in models with long-term income. The coefficients of the short-term income dummy variables fall sharply in magnitude and many lose significance when we include covariates such as maternal characteristics in the models. However, the coefficients of the variables representing maternal characteristics, child nutritional status, and infant health outcomes do not differ much between models with short-term and those with long-term income controls. ${ }^{8}$

Finally, Table 7 presents coefficients of long-term income/needs dummy variables from models that do [specification (1)] and do not [specification (2)] control for scores on the HOME assessment. (Specification (1) is the same as reported in Table 5.) Addition of the HOME score lowers the partial effects of poverty by roughly one-quarter to one-half for most cognitive indicators. The coefficient of the HOME score is large and statistically significant in all models.

\section{DISCUSSION AND CONCLUSIONS}

We find evidence of substantial disadvantages in cognitive development among young children in chronically poor families in the United States. Deficits are apparent in eight different indices of cognitive or socioemotional development, including measures of verbal memory, vocabulary, math and reading achievement, and an index of behavior problems. Consistent with the findings of Duncan et al. (1994) from their analysis of five-year-old children who had low weight at birth, we found larger differentials in cognitive scores when we used long-term rather than short-term measures of poverty status. We extend their results to a national sample of children that includes both low- and normalbirth-weight children, and a wider range of ages (up to age eleven in some cases). Our findings demonstrate the importance of long-term measures of economic disadvantage (and thus longitudinal data) for estimating the effects on child development of growing up poor. 
TABLE 7

Coefficients of Long-Term Income/Needs Variables from OLS Regressions with and without Control for HOME Assessment Score

Tests of Child

Development

(Dependent Variables)

13-Year Income/Needs Ratio

\begin{tabular}{lllll}
\hline$<0.5$ & $0.5-1.0$ & $1.0-1.85$ & $1.85-3.0$ & HOME
\end{tabular}

$\underline{\text { PPVT }}$

(1)

(2)

$-10.0^{*}$

$-10.1^{*}$

$-7.5^{*}$

$-5.3^{*}$

$-4.4^{*}$

$-5.3^{*}$

$-6.1^{*}$

$-3.2^{*}$

$0.22 *$

$\underline{\mathrm{VMAB}}$

(1)

(2)

$-2.5$

1.0

$3.3 *$

2.6

0.4

3.6

$4.7 *$

$3.3 *$

$0.14 *$

$\frac{\mathrm{VMC}}{(1)}$

(2)

$-4.7$

$-0.1$

1.2

2.8

$-2.2$

2.1

2.4

$3.3 *$

$0.13 *$

SPAN

(1)

$-5.8 *$

$-5.3^{*}$

$-2.0$

$-1.6$

$-4.3$

-4.0 *

$-1.1$

$-0.9$

$0.07 *$

$\underline{\mathrm{BPI}}^{\mathrm{a}}$

(1)

(2)

\section{4}

$7.1 *$

$5.7 *$

$3.8^{*}$

1.5

$3.8^{*}$

$3.8 *$

$2.8^{*}$

$-0.18^{*}$

$\underline{\text { PIATM }}$

$-11.3^{*}$

$-7.8^{*}$

$-4.2 *$

$-1.7$

$-8.2^{*}$

$-5.1^{*}$

$-2.5$

$-0.7$

$0.15^{*}$

PIATRR

(1)

(2)

$-11.0 *$

$-9.0 *$

$-5.3^{*}$

$-2.4$

$-8.6^{*}$

$-6.8^{*}$

$-4.1 *$

$-1.7$

$0.12 *$

PIATRC

$-6.9 *$

$-6.1^{*}$

$-2.9$

0.9

$-4.9$

$-4.4^{*}$

$-1.8$

1.5

$0.10 *$

Source: Authors' calculations based on 1979-1991 National Longitudinal Survey of Youth.

\section{Model specifications:}

(1) Excludes HOME score.

(2) Includes HOME score.

Notes: Controls include, in addition to income variables, dummy variables for black and Hispanic, boy, first born, marital status (2), schooling (2), LBW, short at birth, $\mathrm{LBW}^{*}$ short, gestation <37 weeks, alcohol drinking (3) and smoking (3) during pregnancy, and controls for number of siblings, age of child at assessment (in months), mother's AFQT, and age at first birth (number of dummy variables for each item are in parentheses). See Table A1 for descriptions of the tests. Sample sizes appear at the bottom of Table 4. SPAN is raw score $(\max =20)$ times five; all others are age-standardized percentile scores.

${ }^{\mathrm{a} A}$ higher BPI score indicates more behavior problems.

$* \mathrm{p} \leq .05$. 
Our results differ from those of previous studies that have found modest effects of income. For example, Haveman and Wolfe (1993, p. 169), in a recent article that summarizes their forthcoming book on the determinants of child well-being, conclude that "Economic circumstances, like the level of family income relative to needs, have a persistently positive effect on children, though this linkage does not appear to be quantitatively large." We suspect that this conclusion may reflect the use of short-term income measures in the studies reviewed. In this respect, our results parallel those of Solon (1992) and Zimmerman (1992), who show that the use of single-year income or wage measures lead to substantial understatements of the intergenerational correlation in economic standing.

The developmental disadvantages of long-term poor children appear not to be accounted for by maternal and familial characteristics associated with poverty, such as family structure, maternal educational attainment, or academic ability. In models that control for these factors, differentials by long-term income/needs ratios remain large, with poverty negatively related to performance on cognitive assessments. Several familial characteristics are significantly related to cognitive test scores. In models that include controls for long-term income, maternal characteristics, and child's nutritional status at the time of assessment, black racial identification is associated with lower scores on the PPVT, but with higher scores on the VMAB, VMC, SPAN, and PIATRR tests, whether or not maternal AFQT score is controlled. This finding should raise a flag of caution about studies that employ a single indicator of cognitive and socioemotional development, especially those using the NLSY that have relied exclusively upon the PPVT score. Because the PPVT score measures receptive vocabulary for Standard American English, the results may indicate that black children, on average, are not learning Standard American English at the same rate as white children (see, e.g., Labov and Harris [1986]), but are not otherwise cognitively or socioemotionally impaired when differences across racial and ethnic groups in long-term income, nutritional status at assessment, and health in infancy are taken into account. We found little difference in cognitive test scores according to family structure as 
measured by mother's marital status at the time of the assessment, in models that also controlled for long-term poverty status and other characteristics of the mother and household. This finding is particularly striking when one considers the substantial differences in marital status across income groups in our sample: nearly half of the chronically (very) poor women were never married, and an additional 25 percent were separated or divorced, compared to only 9 percent never married and 5 percent divorced or separated among women in the highest income group. The absence of evidence of a direct effect of family structure on child development, once long-term income/needs ratios are controlled, distinguishes our findings from those of previous studies (e.g., those reviewed by Danziger and Stern [1990]), although prior studies generally have not employed controls for long-term economic standing of the family, child nutritional status at assessment, and health at birth.

There were consistently positive effects of higher levels of maternal education in multivariate models of child cognitive development that included controls for maternal AFQT and long-term income/needs ratios. This result suggests a beneficial effect of maternal education for child development, beyond its correlation with income or maternal academic aptitude.

Aspects of the home environment measured by the HOME (Home Observation for Measurement of the Environment) assessment appear to be important mediators of the effects of long-term poverty on child development. This result is consistent with those of other studies of cognitive and socioemotional development that use NLSY data (e.g., Luster and Dubow [1992], who study PPVT scores; Baker and Mott [1992], who study BPI and PIATM and PIATRR scores), although those studies do not consider long-term poverty. Scores on the HOME assessment account for one-third to one-half of the cognitive disadvantages of children from chronically poor families. We believe this result must be interpreted with caution until further systematic exploration of the importance of individual components of the HOME assessment can be carried out. In particular, it would be useful to isolate the effects of those items that are genuine observations of parenting 
behavior or cognitive stimulation versus those that are more closely linked to income such as material aspects of the home.

Our estimates of the mediating effect of the HOME score on the cognitive disadvantages of poor children are lower than estimates of the mediating effect of HOME scores on the IQs of poor children (Goldstein 1990). ${ }^{9}$ The difference between our estimates and those reported by Goldstein may be due to differences in outcome measures used, or it may result from the fact that the studies she reviewed lacked adequate measures of long-term income. Where controls for long-term income are lacking, the HOME score would measure both aspects of the home environment and the long-term income/needs ratio of the child's family.

Finally, our analyses provide evidence that poor nutritional status contributes to impaired cognitive development. Children who are low height-for-age or low weight-for-height have lower scores on tests of cognitive and socioemotional development. Low birth weight and short height at birth are also associated with poor cognitive outcomes. However, nutritional status and infant health variables explain little of the variation in developmental scores across income groups.

Future research objectives include exploring further the causes of developmental disadvantages experienced by poor children and identifying appropriate public policy strategies. Our results confirm that poor children in the United States are at heightened developmental risk in early childhood and show that these risks are substantial among the long-term poor. Our findings suggest that cash assistance should be given renewed consideration in the search for policies to help reduce developmental deficits among poor children. Our finding that cognitive development is also related to deficits in nutritional status suggests that nutritional interventions, such as WIC or subsidized meals, may improve child development. Initiatives that seek to increase educational attainment among poor women would also appear useful. Although one may be tempted to draw further conclusions about the expansion of specific social programs from our results, we believe that such conclusions would be 
premature. Such a recommendation would be more appropriately based upon specific program evaluations or behavioral models that allow the effects of such programs to be simulated (e.g., Garfinkel and Manski [1992]). 
TABLE A1

Description of Tests of Socioemotional and Cognitive Development

\begin{tabular}{|c|c|c|c|}
\hline Test & Objective & Format & Ages \\
\hline $\begin{array}{l}\text { Home Observation for Measurement of } \\
\text { the Environment-Short Form (HOME) }\end{array}$ & $\begin{array}{l}\text { To assess the amount of emotional support } \\
\text { and cognitive stimulation in the child's } \\
\text { environment. }\end{array}$ & $\begin{array}{l}\text { Two components: a. Interviewer observation of mother-child } \\
\text { interaction and safety/appearance of home. b. Maternal report } \\
\text { of child's interaction with adult family members, discipline } \\
\text { methods, and materials and activities available to child. }\end{array}$ & $\begin{array}{l}\text { Four versions: } \\
\text { Birth-2 } \\
\text { 3-5 years } \\
\text { 6-9 years } \\
10+\text { years }\end{array}$ \\
\hline $\begin{array}{l}\text { McCarthy Scale of Children's } \\
\text { Abilities: Verbal Memory Subscales } \\
\text { (VMAB and VMC) }\end{array}$ & $\begin{array}{l}\text { To assess short-term memory for verbal } \\
\text { stimuli. }\end{array}$ & $\begin{array}{l}\text { AB: Child repeats words or sentences said by the interviewer. } \\
\mathrm{C} \text { : Child listens to and retells a short story. }\end{array}$ & $3-6$ years \\
\hline $\begin{array}{l}\text { Peabody Picture Vocabulary } \\
\text { Test-Revised (PPVT) }\end{array}$ & $\begin{array}{l}\text { To measure receptive vocabulary for } \\
\text { Standard American English. }\end{array}$ & $\begin{array}{l}\text { Interviewer says a word and the child points to one of four } \\
\text { pictures which best portrays the meaning of the word. }\end{array}$ & $3+$ years \\
\hline Memory for Digit Span (SPAN) & To measure short-term memory. & $\begin{array}{l}\text { Child repeats a sequence of numbers then repeats a different } \\
\text { sequence in reverse order. Length of sequence increases with } \\
\text { correct answers. }\end{array}$ & $7+$ years \\
\hline Behavior Problem Index (BPI) & $\begin{array}{l}\text { To measure the frequency, range, and type of } \\
\text { childhood behavior problems. }\end{array}$ & $\begin{array}{l}\text { Mothers respond to twenty-eight questions on specific problem } \\
\text { behaviors by stating whether each was often true, sometimes } \\
\text { true, or not true of the child in past three months. }\end{array}$ & $4+$ years \\
\hline $\begin{array}{l}\text { Peabody Individual Achievement Test: } \\
\text { Math Subscale (PIAT-M) }\end{array}$ & $\begin{array}{l}\text { To measure academic achievement in } \\
\text { mathematics as taught in mainstream } \\
\text { education. }\end{array}$ & $\begin{array}{l}\text { Test consists of eighty-four multiple-choice items of increasing } \\
\text { difficulty. Child looks at problem and then points to the } \\
\text { answer. }\end{array}$ & $5+$ years \\
\hline $\begin{array}{l}\text { Peabody Individual Achievement Test: } \\
\text { Reading Recognition Subscale (PIAT- } \\
\text { RR) }\end{array}$ & $\begin{array}{l}\text { To measure word recognition and } \\
\text { pronunciation ability. }\end{array}$ & $\begin{array}{l}\text { Test consists of eighty-four multiple-choice items of increasing } \\
\text { difficulty. Child matches letter, names letters, and reads single } \\
\text { words aloud. }\end{array}$ & $5+$ years \\
\hline $\begin{array}{l}\text { Peabody Individual Achievement Test: } \\
\text { Reading Comprehension Subscale } \\
\text { (PIAT-RC) }\end{array}$ & $\begin{array}{l}\text { To measure the ability to derive meaning } \\
\text { from sentences that are read silently. }\end{array}$ & $\begin{array}{l}\text { Test consists of sixty-six items of increasing difficulty. Child } \\
\text { silently reads a sentence once and then selects one of four } \\
\text { pictures which best portrays the meaning of the sentence. }\end{array}$ & $5+$ years \\
\hline
\end{tabular}

Source: Geronimus, Korenman, and Hillemeier (1994). 
TABLE A2

\section{Coefficients of Long-Term Income/Needs Variables from Models of Cognitive Development, by Race}

\begin{tabular}{|c|c|c|c|c|c|c|c|c|}
\hline \multirow{2}{*}{$\begin{array}{l}\text { 13-Year } \\
\text { Income/Needs Ratio }\end{array}$} & \multirow[b]{2}{*}{ PPVT } & \multirow[b]{2}{*}{ VMAB } & \multirow[b]{2}{*}{ VMC } & \multirow[b]{2}{*}{ SPAN } & \multirow[b]{2}{*}{$\mathrm{BPI}^{\mathrm{a}}$} & \multicolumn{3}{|c|}{ PIAT } \\
\hline & & & & & & $\overline{\mathrm{M}}$ & RR & $\mathrm{RC}$ \\
\hline \multicolumn{9}{|l|}{ Hispanics } \\
\hline$<0.5$ & $-14.1 *$ & -1.4 & $-13.5 \#$ & 2.7 & $14.5^{*}$ & $-23.1^{*}$ & $-18.9 *$ & -6.1 \\
\hline $0.5-1.0$ & $-14.3 *$ & -0.3 & -1.2 & -3.8 & $10.0 *$ & $-7.6 \#$ & -6.1 & -1.8 \\
\hline $1.0-1.85$ & $-8.7^{*}$ & 2.0 & -2.1 & -1.0 & $7.0 \#$ & -5.0 & -0.2 & 2.9 \\
\hline $1.85-3.0$ & $-7.3^{*}$ & 1.3 & -1.3 & -2.8 & 5.4 & 0.8 & 0.1 & 3.7 \\
\hline Adjusted $\mathrm{R}^{2}$ & .19 & .13 & .11 & .10 & .08 & .13 & .19 & .42 \\
\hline Sample size & 764 & 718 & 701 & 376 & 764 & 642 & 634 & 434 \\
\hline \multicolumn{9}{|l|}{ Non-Hispanic Blacks } \\
\hline$<0.5$ & $-10.4^{*}$ & -4.6 & -1.6 & -2.0 & 3.7 & -4.6 & -6.8 & -3.8 \\
\hline $0.5-1.0$ & $-8.5^{*}$ & 1.5 & 1.4 & -0.9 & 5.6 & -3.3 & -5.7 & -3.2 \\
\hline $1.0-1.85$ & $-6.2 *$ & 3.5 & 3.5 & 2.8 & 1.6 & 0.1 & -2.5 & -1.2 \\
\hline $1.85-3.0$ & -2.8 & 2.8 & 6.9 & 0.4 & 4.4 & 0.7 & -2.0 & 2.8 \\
\hline Adjusted $\mathrm{R}^{2}$ & .12 & .09 & .07 & .06 & .02 & .01 & .17 & .42 \\
\hline Sample size & 1178 & 1145 & 1127 & 569 & 1122 & 1004 & 988 & 738 \\
\hline \multicolumn{9}{|c|}{ Non-Hispanic Whites and Others } \\
\hline$<0.5$ & $-12.9 *$ & -4.6 & -6.4 & $-12.1 \#$ & -6.7 & $-13.0 *$ & -8.1 & 0.5 \\
\hline $0.5-1.0$ & $-8.3 *$ & 1.3 & 0.2 & $-7.4^{*}$ & $5.3 \#$ & $-10.3^{*}$ & $-11.6^{*}$ & $-10.0^{*}$ \\
\hline $1.0-1.85$ & $-4.9 *$ & 5.2 & 2.4 & $-4.3^{*}$ & $6.8^{*}$ & $-4.6^{*}$ & $-7.9 *$ & $-6.3 *$ \\
\hline $1.85-3.0$ & -2.5 & $3.7 *$ & $3.4 \#$ & -1.3 & 2.3 & -2.8 & $-2.9 \#$ & 0.3 \\
\hline Adjusted $\mathrm{R}^{2}$ & .20 & .08 & .03 & .07 & .06 & .14 & .20 & .29 \\
\hline Sample size & 1884 & 1831 & 1798 & 694 & 1710 & 1397 & 1382 & 972 \\
\hline
\end{tabular}

Source: Authors' calculations based on 1979-1991 National Longitudinal Survey of Youth.

Notes: Controls include age of child, boy, and first born; mother's AFQT score, age at first birth, marital status at assessment (2 dummy variables), and highest grade completed by 1991 (2 dummy variables); and dummy variables for stunted and wasted at assessment, and LBW, short, premature birth, and an interaction of $\mathrm{LBW}^{*}$ short.

$* \mathrm{p} \leq .05$.

$\# .05<\mathrm{p} \leq .10$. 
TABLE A3

Coefficients (Standard Errors) of Continuous Long-Term Income/Needs and Short-Term Income/Needs Variables from Two Models of Child Cognitive or Socioemotional Development

\begin{tabular}{lcccccccc}
\hline & & & & & & & \multicolumn{2}{c}{ PIAT } \\
\cline { 5 - 8 } & PPVT & VMAB & VMC & SPAN & BPI & M & RR & RC \\
\hline $\begin{array}{l}\text { Model (1): includes } \\
\begin{array}{l}13 \text {-year income/needs } \\
\text { ratio }\end{array}\end{array}$ & $2.5^{*}$ & -0.2 & 0.4 & $1.1^{*}$ & $-2.2^{*}$ & $2.3^{*}$ & $2.5^{*}$ & $1.8^{*}$ \\
& $(0.4)$ & $(0.5)$ & $(0.5)$ & $(0.5)$ & $(0.5)$ & $(0.5)$ & $(0.5)$ & $(0.5)$ \\
$\begin{array}{l}\text { Model (2): includes } \\
\begin{array}{l}1 \text {-year income/needs } \\
\text { ratio }\end{array}\end{array}$ & $1.2^{*}$ & 0.4 & 0.3 & 0.5 & $-1.3^{*}$ & $0.9^{*}$ & $1.0^{*}$ & $0.8^{*}$ \\
\hline
\end{tabular}

Source: Authors' calculations based on 1979-1991 National Longitudinal Survey of Youth.

Notes: Controls in each model include age of child, boy, and first born; mother's AFQT score, age at first birth, marital status at assessment ( 2 dummy variables), highest grade completed by 1991 ( 2 dummy variables), and behaviors (smoking, drinking and cocaine use); and dummy variables for stunted and wasted at assessment, and LBW, short, premature birth, and an interaction of $\mathrm{LBW}^{*}$ short.

$* \mathrm{p} \leq .05$. 
TABLE A4

\section{Coefficients of Long-Term and Short-Term Income/Needs Dummy Variables from Models of Child Cognitive and Socioemotional Development that Include Both Short-Term and Long-Term Income/Needs Variables}

\begin{tabular}{|c|c|c|c|c|c|c|c|c|}
\hline & \multirow[b]{2}{*}{ PPVT } & \multirow[b]{2}{*}{ VMAB } & \multirow[b]{2}{*}{ VMC } & \multirow[b]{2}{*}{ SPAN } & \multirow[b]{2}{*}{ BPI } & \multicolumn{3}{|c|}{ PIAT } \\
\hline & & & & & & $\mathrm{M}$ & $\mathrm{RR}$ & $\mathrm{RC}$ \\
\hline \multicolumn{9}{|c|}{ 1-year income/needs ratio } \\
\hline$<0.5$ & -1.1 & -0.4 & -0.4 & -0.1 & $5.4^{*}$ & -0.5 & -1.5 & -2.8 \\
\hline $0.5-1.0$ & $-3.2 *$ & -3.1 & -2.0 & 0.9 & 2.9 & -3.0 & -2.5 & $-4.2 *$ \\
\hline $1.0-1.85$ & $-3.5^{*}$ & -2.8 & -1.7 & -0.5 & $5.1^{*}$ & -0.3 & -2.0 & -3.3 \\
\hline $1.85-3.0$ & -1.0 & 0.2 & 0.9 & 0.7 & $3.8^{*}$ & 0.0 & 0.2 & -1.4 \\
\hline \multicolumn{9}{|c|}{ 13-year income/needs ratio } \\
\hline$<0.5$ & $-8.7^{*}$ & -1.6 & -3.8 & $-5.9 *$ & 2.6 & $-10.4 *$ & $-9.6^{*}$ & -4.7 \\
\hline $0.5-1.0$ & $-8.3^{*}$ & 2.6 & 1.1 & $-5.4 *$ & $4.6^{*}$ & $-6.7^{*}$ & $-7.5 *$ & -3.6 \\
\hline $1.0-1.85$ & $-5.7^{*}$ & $4.7 *$ & 2.2 & -1.9 & 3.1 & $-3.7^{*}$ & $-4.2 *$ & -1.0 \\
\hline $1.85-3.0$ & $-3.6^{*}$ & $3.1^{*}$ & 2.9 & -1.7 & 2.0 & -1.6 & -2.1 & 1.9 \\
\hline
\end{tabular}

Source: Authors' calculations based on 1979-1991 National Longitudinal Survey of Youth.

Notes: Controls include age of child, boy, and first born; mother's AFQT score, age at first birth, marital status at assessment ( 2 dummy variables), and highest grade completed by 1991 (2 dummy variables); and dummy variables for stunted and wasted at assessment, and LBW, short, premature birth, and an interaction of $\mathrm{LBW}^{*}$ short.

$* p \leq .05$. 
TABLE A5

Sample Sizes by Test of Child Cognitive and Socioemotional Development and Long-Term Income/Needs Ratio

\begin{tabular}{lrrrrrrrr}
\hline & PPVT & SPAN & BPI & PIATM & PIATRR & PIATRC & VMAB & VMC \\
\hline$<0.5$ & 157 & 78 & 159 & 135 & 134 & 97 & 149 & 147 \\
$0.5-1.0$ & 834 & 374 & 792 & 681 & 667 & 528 & 809 & 791 \\
$1.0-1.85$ & 1254 & 565 & 1160 & 1003 & 994 & 849 & 1201 & 1176 \\
$1.85-3.0$ & 990 & 420 & 939 & 798 & 790 & 669 & 965 & 957 \\
$3.0+$ & 591 & 202 & 546 & 426 & 419 & 340 & 570 & 555 \\
Total & 3826 & 1639 & 3596 & 3043 & 3004 & 2483 & 3694 & 3626 \\
\hline
\end{tabular}

Source: 1979-1991 National Longitudinal Survey of Youth.

Note: See Table A1 for names and descriptions of tests. Long-term income/needs is a thirteen-year average, 1978-1990. 


\section{Notes}

${ }^{1}$ Information on infants born before 1983 was collected during the 1983 or 1986 interview (Center for Human Resource Research 1991).

${ }^{2}$ For example, states may not set WIC eligibility levels above 1.85 times the poverty line, a cutoff point for one of our categories of income/needs ratios.

${ }^{3}$ All of the infant health variables are based on maternal reports. Studies suggest that maternal recalls of birth-weight are reliable (Burns et al. 1987; Little 1986), but those of gestational age may not be.

${ }^{4} \mathrm{NLSY}$ mothers were also asked about cocaine use in the year prior to the birth of each child, but only a minuscule fraction reported cocaine use. For some outcomes there were no children whose mother reported cocaine use and hence no effect could be estimated. When effects could be estimated, they were generally large and negative (adversely affecting development), but had very large standard errors. Adding the cocaine variable to the models did not change the other coefficients.

${ }^{5}$ In our earlier work we found that the effect of the presence of the biological father in the child's household had a significant effect on only one of eight developmental outcomes in models that also included marital status and income (Miller and Korenman 1993, Table 11).

${ }^{6}$ The results from separate models for Hispanic, black, and white children are presented in Table A2. There are similar differentials by long-term income/needs ratio within each group; however, some effects are not statistically significant for these subsamples, possibly due to smaller sample sizes. The only consistent difference in the patterns of coefficients across the three groups was a large effect of low birth weight on child development among blacks.

${ }^{7}$ In other words, our finding of larger effects of long-term compared to single-year poverty is not due to the fact that an absolute income threshold (e.g., less than half the poverty line) captures a more extreme portion of the long-term income distribution.

${ }^{8}$ Appendix Tables A3 and A4 present results of additional analyses of differences in the effects of long-term and short-term poverty on child development. In Table A3 we compare the coefficients of 
two "continuous" income/needs variables, one short-term and one long-term. For six of the eight outcomes, differentials in child development according to long-term income are roughly twice as large as the corresponding differential by short-term income. (These results are from separate models.) In Table A4 we include controls for both short-term and long-term income/needs categories in the same models. In most cases coefficients of the long-term income categories remain large and statistically significant, while those of the short-term categories shrink considerably and many are no longer statistically significant at the .05 level. An exception to this pattern is the BPI, which appears to be more sensitive to short-term than to long-term poverty.

${ }^{9}$ Goldstein reported that scores on the HOME assessment account for 50 to 70 percent of the difference in IQ scores between low and high SES children. 


\section{References}

Baker, P. C. and F. L. Mott. 1989. NLSY Child Handbook, 1990. Columbus, Ohio: Center for Human Resources Research, The Ohio State University.

Baker, P. C. and F. L. Mott. 1992. "Following Children over Time: Child Development and Its Linkages with Family Social and Economic Transitions." Presented at the Statistics Canada Symposium on Design and Analysis of Longitudinal Surveys.

Bane, M. J. and D. T. Ellwood. 1986. "Slipping Into and Out of Poverty: The Dynamics of Spells." Journal of Human Resources 21: 1-23.

Beaton, G. H. 1983. "Energy and Human Nutrition: Perspectives and Problems." Nutrition Reviews 41: 325-340. Blackburn, McK. 1993. "International Comparisons of the Extent of Extreme Poverty." Presented at the National Bureau of Economic Research Pre-conference on Extreme Poverty in Industrialized Countries, January 21.

Broman, S. H., P. L. Nichols, and W. A. Kennedy. 1975. Preschool IQ: Prenatal and Early Developmental Correlates. Hillsdale, New Jersey: Erlbaum.

Burns, T. L., P. P. Moll, C. A. Rost, et al. 1987. "Mothers Remember Birthweights of Adolescent Children: The Muscatine Ponderosity Family Study." International Journal of Epidemiology 16: 550-555.

Caldwell, B. M. and R. H. Bradley. 1979. Home Observation for Measurement of the Environment. Center for Child Development and Education, Little Rock, Arkansas.

Center for Human Resource Research. 1991. Maternal-Child Health Data from the NLSY: 1988 Tabulations and Summary Discussion. The Ohio State University, Columbus, Ohio, October.

Center for Human Resource Research. 1989. NLSY Child Handbook 1989. The Ohio State University, Columbus, Ohio.

Center for Human Resource Research. 1988. NLSY Merged Child-Mother File Codebook. The Ohio State University, Columbus, Ohio.

Currie, J. and N. Cole. 1991. "Does Participation in Transfer Programs during Pregnancy Improve Birth Weight?" National Bureau of Economic Research Working Paper No. 3832, Cambridge, Mass. 
Danziger, S. and J. Stern. 1990. "The Causes and Consequences of Child Poverty in the United States." University of Michigan Population Studies Center Research Report No. 90-194, September.

Desai, S., R. T. Michael, and P. L. Chase-Lansdale. 1990. "The Home Environment: A Mechanism through which Maternal Employment Affects Child Development." Research Division Working Paper No. 20, Population Council, New York.

Duncan, G. J., J. Brooks-Gunn, and P. K. Klebanov. 1994. "Economic Deprivation and Early-Childhood Development." Child Development 65(2): 296-318.

Duncan, G. J., R. D. Coe, M. E. Corcoran, et al. 1984. Years of Poverty, Years of Plenty. Ann Arbor, Mich.: Institute for Social Research.

Duncan, G. J. and W. L. Rodgers. 1991. "Has Child Poverty Become More Persistent?" American Sociological Review 56: 538-550.

Ellwood, D. T. 1988. Poor Support. New York: Basic Books.

Freeman, H. E., R. E. Klein, J. W. Townsend, and A. Lechtig. 1980. "Nutritional and Cognitive Development among Rural Guatemalan Children." American Journal of Public Health 70(12): 1277-1285.

Garfinkel, I. and C. Manski. 1992. Evaluating Welfare and Training Programs. Cambridge, Mass.: Harvard University Press.

Geronimus, A. T., S. Korenman, and M. M. Hillemeier. 1994. "Does Young Maternal Age Adversely Affect Child Development? Evidence from Cousin Comparisons." Population and Development Review. Forthcoming. Goldstein, N. 1990. "Explaining Socioeconomic Differences in Children's Cognitive Test Scores." John F. Kennedy School of Government, Harvard University, January.

Haveman, R. and B. Wolfe. 1993. "Children's Prospects and Children's Policy." Journal of Economic Perspectives 7(4): $153-174$.

Korenman, S. and J. E. Miller. 1992. "Food Stamp Program Participation and Maternal and Child Health." Final Report to the Food and Nutrition Service, U.S. Department of Agriculture. 
Kotelchuck, M., J. Schwartz, M. Anderka, and D. Finison. 1984. "WIC Program Participation and Pregnancy Outcomes: Massachusetts Statewide Evaluation Project." American Journal of Public Health 74: 1086-1092.

Labov, W. and W. A. Harris. 1986. "De Facto Segregation of Black and White Vernaculars." In D. Sankoff, ed., Diversity and Diachrony. Philadelphia: John Benjamins Co., pp. 1-24.

Lasky, R. E., R. E. Klein, C. Yarbrough, P. L. Engle, and R. Martorell. 1981. "The Relationship between Physical Growth and Infant Behavioral Development in Rural Guatemala." Child Development 52: 219-226.

Little, R. E. 1986. "Birthweight and Gestational Age: Mother's Estimates Compared with State and Hospital Records." American Journal of Public Health 76: 1350-1351.

Luster, T. and E. R. Dubow. 1992. "Home Environment and Maternal Intelligence as Predictors of Verbal Intelligence: A Comparison of Preschool and School Age Children." Merrill-Palmer Quarterly 38(2): 151-175. Miller, J. E. and S. Korenman. 1993. "Poverty, Nutritional Status, Growth, and Cognitive Development of Children in the United States." Office of Population Research Working Paper No. 93-5, Princeton University, June. Miller, J. E. and S. Korenman. 1994. Poverty and Children's Nutritional Status in the United States 140(3): 233-243.

Parcel, T. L. and E. G. Menaghan. 1989. "Child Home Environment as a Mediating Construct between SES and Child Outcomes." Mimeo, The Ohio State University, Department of Sociology.

Pollitt, E. 1988. "Developmental Impact of Nutrition on Pregnancy, Infancy, and Childhood: Public Health Issues in the United States." In N. W. Bray, ed., International Review of Research in Mental Retardation, Vol. 15. Academic Press.

Solon, G. 1992. "Intergenerational Income Mobility in the United States." American Economic Review 82(3): 393-408.

Sullivan, K. M., and J. Gorstein. 1990. "ANTHRO: Software for Calculating Pediatric Anthropometry, Version 1.01." U.S. Department of Health and Human Services, Public Health Service, Centers for Disease Control, Atlanta, Georgia, and the Nutrition Unit, World Health Organization, Geneva, Switzerland. 
Townsend, J. W., R. E. Klein, M. H. Irwin, W. Owens, C. Yarbrough, and P. L. Engels. 1982. "Nutrition and Preschool Mental Development." In D. A. Wagner and H. W. Stevenson, eds., Cultural Perspectives on Child Development. San Francisco: W. H. Freeman and Company, pp. 124-145.

U.S. Bureau of the Census, Current Population Reports, Series P-60. Various years. Money Income of Households, Families, and Persons in the United States. Washington, D.C.: U.S. Government Printing Office.

U.S. Bureau of the Census, Current Population Reports, Series P-60, No. 138. 1983. Characteristics of Persons below the Poverty Level: 1981. Washington, D.C.: U.S. Government Printing Office.

U.S. Bureau of the Census. 1989. Statistical Abstract of the United States: 1989. 109th edition. Washington, D.C.: U.S. Government Printing Office.

Wilson, A. B. 1981. "Longitudinal Analysis of Diet, Physical Growth, Verbal Development and School Performance." In J. B. Balderston, A. B. Wilson, M. E. Freire and M. S. Simonen, eds., Malnourished Children of the Rural Poor. Boston: Auburn House.

Wilson, D. M., L. D. Hammer, P. M. Duncan, S. M. Dornbusch, P. L. Ritter, R. L. Hintz, R. T. Gross, and R. G. Rosenfeld. 1986. "Growth and Intellectual Development." Pediatrics 78: 646-650.

World Health Organization Working Group. 1986. "Use and Interpretation of Anthropometric Indicators of Nutritional Status." Bulletin of the World Health Organization 64(6): 929-941.

Zimmerman, R. 1992. "Regression toward Mediocrity in Economic Stature." American Economic Review 82(3): 409-429. 